\title{
Superparamagnetic calcium ferrite nanoparticles synthesized using a simple sol- gel method for targeted drug delivery
}

\author{
N.H. Sulaiman ${ }^{\mathrm{a}}$, M.J. Ghazali, ${ }^{\mathrm{a}, \mathrm{b},}$, B.Y. Majlis ${ }^{\mathrm{b}}, \mathrm{J}_{\text {. Yunas }}^{\mathrm{b}}$ and M. Razali ${ }^{\mathrm{a}, \mathrm{c}}$ \\ ${ }^{a}$ Department of Mechanical and Materials Engineering, Faculty of Engineering and Built \\ Environment, Universiti Kebangsaan Malaysia, 43600 Bangi, Malaysia \\ ${ }^{b}$ Institute of Microengineering and Nanoelectronics, Universiti Kebangsaan Malaysia, 43600 Bangi, \\ Malaysia \\ ${ }^{c}$ Department of Management office, Faculty of Dentistry, Universiti Kebangsaan Malaysia, 43600 \\ Bangi, Malaysia
}

\begin{abstract}
The calcium ferrite nano-particles $\left(\mathrm{CaFe}_{2} \mathrm{O}_{4} \mathrm{NPs}\right)$ were synthesized using a sol-gel method for targeted drug delivery application. The proposed nano-particles were initially prepared by mixing calcium and iron nitrates that were added with citric acid in order to prevent agglomeration and subsequently calcined at a temperature of $550^{\circ} \mathrm{C}$ to obtain small particle size. The prepared nanoparticles were characterized by using an XRD (X-ray diffraction), which revealed the configuration of orthorhombic structures of the $\mathrm{CaFe}_{2} \mathrm{O}_{4}$ nano-particles. A crystallite size of $\sim 13.59 \mathrm{~nm}$ was obtained using a Scherer's formula. Magnetic analysis using a VSM (Vibrating Sample Magnetometer analysis), revealed that the synthesized particles exhibited super-paramagnetic behavior having magnetization saturation of approximately $88.3 \mathrm{emu} / \mathrm{g}$. Detailed observation via the scanning electron microscopy (SEM) showed the calcium ferrite nano-particles were spherical in shape.
\end{abstract}

Keywords: Magnetic nanoparticles, superparamagnetic, drug delivery

\section{Introduction}

In recent decades, Calcium Ferrites $\left(\mathrm{CaFe}_{2} \mathrm{O}_{4}\right)$ have been extensively studied due to their essential applications, such as in oxidation catalysts, and for their use in high-temperature sensors, gas absorbers, etc. [1, 2]. In addition, $\mathrm{CaFe}_{2} \mathrm{O}_{4}$ shows remarkable physical characteristics, such as high thermal stability, which makes it applicable over a wide temperature range [3].

On the other hand, $\mathrm{CaFe}_{2} \mathrm{O}_{4}$ nano-particles have been intensively explored as the future delivery system of pharmaceutical drug, because of their unique physical properties, capability to use the functionality of bio-molecular and bio-cell interactions and also for their excellent magnetic property [4]. The potential applications of these magnetic nanoparticles are normally found in cell labeling/cell

\footnotetext{
* Address for correspondence: M.J. Ghazali, Department of Mechanical and Materials Engineering, Faculty of Engineering and Built Environment, Universiti Kebangsaan Malaysia, 43600 Bangi, Malaysia. Tel.: 0060192622075; E-mail: mariyam.j.ghazali@gmail.com.
} 
separation [5, 6], for magnetofection to assist gene delivery [7]. They also serve as, contrast agents for magnetic resonance imaging [8]. Moreover, these nano-particles are also used to create local hyperthermia for selective cancer cells destroy by an external magnetic field radiation, as well as serving as a magnetically targeted carrier system in drug deliveries [9-12].

It was noted that the co-precipitation method was utilized to synthesize superparamagnetic iron oxide nano-particles modified with vinyl-triethoxy-silicane and reactive groups. The methods were used to introduce appropriate particle surface during the synthesis of magnetic nano-particles (metal oxides and ferrites) from aqueous salt solutions. However, uniform particle distributions were difficult to obtain [5].

Therefore, in this work, we synthesized $\mathrm{CaFe}_{2} \mathrm{O}_{4}$ magnetic nano-particles using a sol-gel method. This method has many advantages over other production techniques. Amongst its advantages are simple and cost effective process, achievable pure amorphous phases, monodispersity, uniform particle size, homogeneous microstructure and stable material properties within the sol-gel matrix [13]. In this study, XRD (X-Ray Diffraction) and VSM (Vibrating Sample Magnetometer) were used to characterize the prepared samples.

\subsection{Calcium ferrite nanomaterial}

There are several reports on calcium ferrite nano-particles $\left(\mathrm{CaFe}_{2} \mathrm{O}_{4}\right)$ in the bulk form, used as pigments, anodes in lithium batteries, adsorbents of hydrogen sulfide, and solid catalysts. Chemical stability and biocompatibility are other characteristics that make these particles potentially useful for a broad range of applications [14]. Calcium and iron- based compounds have been explored for possible applications in optical memory devices, and the steel manufacture during deoxidization, desulfuration, and dephosphorization [15]. But very less report are found on the application of calcium ferrite particles for biomedical application.

When compared with other ferrites such as $\mathrm{MnFe}_{2} \mathrm{O}_{4}, \mathrm{NiFe}_{2} \mathrm{O}_{4}, \mathrm{ZnFe}_{2} \mathrm{O}_{4}, \mathrm{CoFe}_{2} \mathrm{O}_{4}$ and $\mathrm{CuFe}_{2} \mathrm{O}_{4}$, it is clear that $\mathrm{CaFe}_{2} \mathrm{O}_{4}$ has a significant advantage; it is biocompatible and eco-friendly due to the presence of $\mathrm{Ca}^{2+}$ instead of heavy metals, $\mathrm{CaFe}_{2} \mathrm{O}_{4}$ also has remarkable characteristics, such as high thermal stability, which makes it appropriate over a wide temperature range. It also possesses lower saturation magnetization properties compared to other ferrites that deter aggregation and expedite dispersion in aqueous solutions [14], resulting more contact and shorter equilibrium time. Calcium ferrite $\left(\mathrm{CaFe}_{2} \mathrm{O}_{4}\right)$ also exhibits a unique orthorhombic structure, as reported elsewhere [16-19].

\subsection{The sol-gel method}

The sol-gel process is an appropriate wet process technique to prepare nano-structured metal oxides. Based on this process, molecular precursors undergo hydroxylation and condensation in a solution to produce a "sol" of nanometric particles. Furthermore, condensation process followed with inorganic polymerization creates a 3-D metal oxide network of wet gel. The process is performed at room temperature, while the final crystal structures are obtained after heat treatments [20].

The properties of a gel depend upon for the structure produced during the sol stage of the sol- gel process. Solvent, temperature, nature, concentration of salt precursors employed, $\mathrm{pH}$, and agitation are the most important parameters that influence the kinetics, growth reactions, hydrolysis, condensation reactions and, thus the structure and properties of the gel [21]. In addition some of magnetic materials for example $\mathrm{Mn}_{2} \mathrm{Fe}_{2} \mathrm{O}_{4}, \mathrm{NiFe}_{2} \mathrm{O}_{4}$ and $\mathrm{CoFe}_{2} \mathrm{O}_{4}$ are fabricated using the sol-gel process [17], due to its simple cost-effective process. 


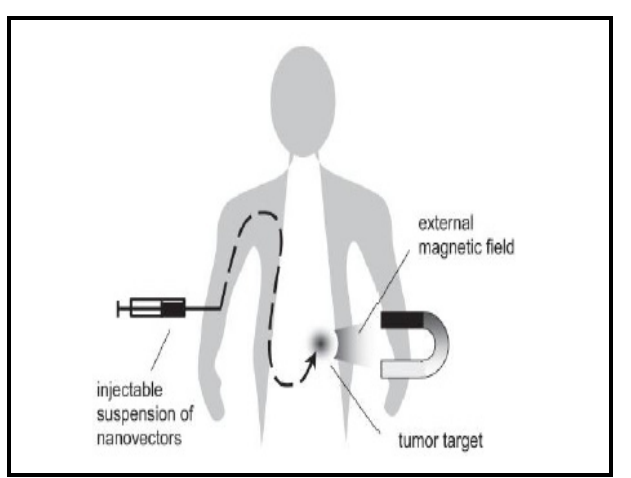

(a)

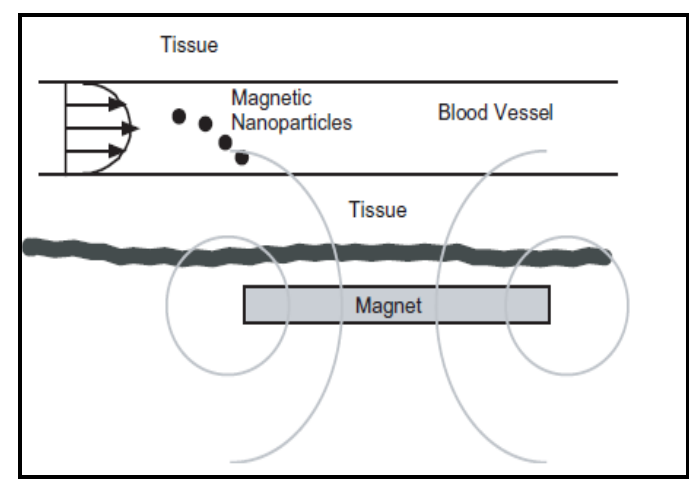

(b)

Fig. 1. Drug Delivery system (a) The mechanism of magnetic-field guided drug delivery system, (b) Cross sectional view of the particle trapping mechanism inside the blood vessel

\section{Mechanism of drug delivery}

In general, the drug delivery mechanism is defined as a formulation or device intended to introduce pharmaceutical agents into the body to achieve a therapeutic effect. This route concerns not only the transportation of the active drug to the right place in the organism but also the controlled release of medicinal substances $[22,23]$. Meanwhile, the magnetic system of drug delivery delivers the magnetic nano-particles loaded with drugs to the tumor locality controlled by an external magnetic field. The fundamental of drug delivery in response to the external magnetic field and particle trapping mechanism are schematically shown in Figures 1(a) and 1(b), respectively. These particles are concentrated in the site selection with the assistance of a magnetic field until the therapy is completed (see Figure 1(b)). Subsequently, they are captured, detected and removed from the body [24]. The main purpose of drug administration is to diminish the dosage through the efficient and precisely targeting of the drug (see Figure 1(b)) [23, 25, 26].

To succeed in delivering drugs into the body, magnetic nanoparticles must have the characteristics of monodispersity, stability superparamagnetism, and biocompatibility [27]. The first requirement is that the size should be controllable, within the size range of a few nanometres up to tens of nanometers $[28,29]$.

The next requirement is the superparamagnetism property. In the case of magnetic properties, nanoparticles should be stable when applied to an external magnetic field [30]. Superparamagnetism is common in sufficiently small ferromagnetic or ferrimagnetic nanoparticles that have a single magnetic domain. These molecules are attracted to a magnetic field, but after the removal of this field they do not retain residual magnetism [31-33].

Nanoparticles with the superparamagnetic property are preferred due to their ability to be magnetized when an external magnetic field exposure is applied. Once the magnetic field is turned off, permanent magnetization (remanence) will disappear. The superparamagnetic property of the material is generated by thermal effects in material during synthesis. With these properties, the injected drug can be directed, localized or heated to a defined location through external magnetic field. Therefore, superparamagnetism in drug delivery is necessary to precisely and quickly detect or capture contaminations in human blood [23]. Superparamagnetism is also essential for drug delivery, which should be induced embolism in blood capillary vessels, and can be avoided.

The other requirement is particle stability for the magnetic nanoparticles used for biomedical 
application, which protects the magnetic core against air oxidation and prevent metal nanoparticles forming aggregates [31], hence ensure permanent biocompatibility. Stability is achieved by coating the core-shell magnetic particle with organic shells. The coating layer includes polymers and other inorganic components such as silica or carbon.

\section{Materials synthesis and characterization}

\subsection{Materials}

Calcium nitrate, Ferric nitrate, Citric acid, Ethelenglycol, and ethanol were purchased from Accot. Lab. Supplies Sdn. Bhd. These chemicals are used for the synthesis process. All reagents were based on analytical grade material with $90 \%$ purity, as shown in Table 1.

\subsection{Sample synthesis}

To achieve a small particle size distribution, calcium ferrite NPs were prepared using a sol-gel method. Initially, calcium nitrate $\mathrm{Ca}\left(\mathrm{NO}_{3}\right)_{2}$ mixed with ferric nitrate $\mathrm{Fe}\left(\mathrm{NO}_{3}\right)_{3}$ of a molar ratio of $1: 1$ $\mathrm{M}$ was dissolved in $100 \mathrm{ml}$ of distilled water with $2 \mathrm{M}$ of citric acid as a chelating agent. The solution was continuously stirred for 4 hours and heated on magnetic stirrer at $80^{\circ} \mathrm{C}$. Then $6 \mathrm{ml}$ of Ethelenglycol was added to the mixture. The flow process is shown in Figure 2.

It was observed that the color of the viscous gel changed from orange to brown. Then, the gel was dried in the oven at $70-80^{\circ} \mathrm{C}$ over night. The obtained particles were calcined at $550^{\circ} \mathrm{C}$ for 2 hours in a furnace. As a result, calcium ferrite nanoparticles powders were obtained.

Table 1

The material composition for the synthesis of calcium ferrite nanoparticles

\begin{tabular}{lllll}
\hline Chemical & Concentration(M) & Volume $(\mathrm{mL})$ & Calculated Weight $(\mathrm{g})$ & Purity \\
\hline Calcium nitrate & 1 & & 5 & $99 \%$ \\
Ferric nitrate & 1 & & 1.5 & $99 \%$ \\
Citric acid & 2 & 6 & 3.8 & $99.5 \%$ \\
Ethelenglycol & & 6 & & $99.5 \%$ \\
Distilled water & 150 & & \\
\hline
\end{tabular}

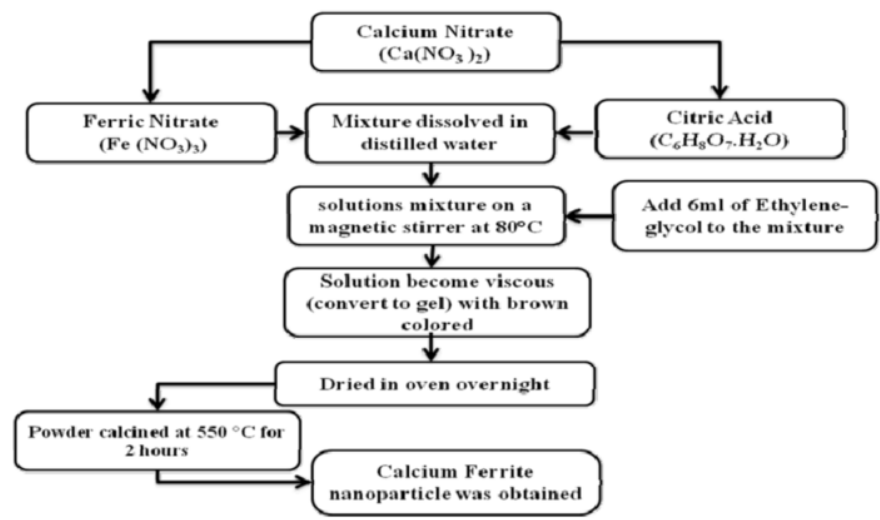

Fig. 2. Flow chart for the preparation of calcium ferrite nanoparticles using sol-gel method. 


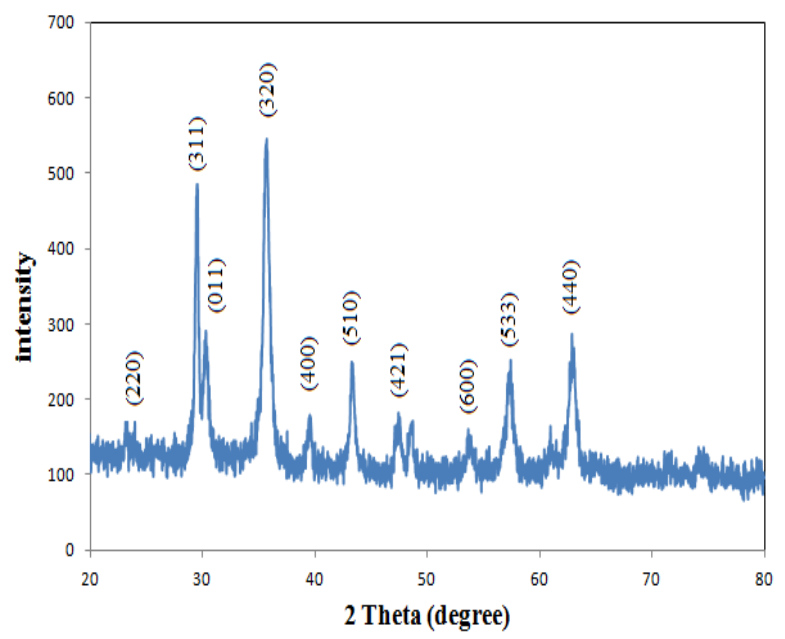

Fig. 3. XRD diffraction pattern of calcium ferrite nanoparticles structure.

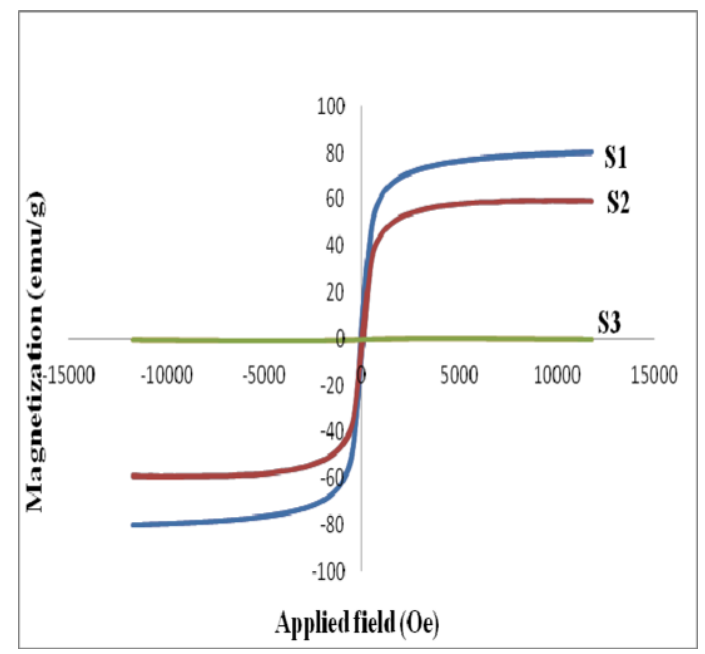

Fig. 4. Paramagnetic characteristic of synthesized calcium ferrite nanoparticles.

\subsection{Characterization of $\mathrm{CaFe}_{2} \mathrm{O}_{4}$}

The crystallite structure and size of the synthesized $\mathrm{CaFe}_{2} \mathrm{O}_{4}$ samples were calculated using an X-ray Powder Diffractometer (XRD) model - D8 ADVANCE BRUKER AXS with $\mathrm{Cu}$ Ka radiation (1.5406 $\AA$ ) in a $2 \mathrm{~h}$ scan range of $20-80$. The magnetic properties of the powders were examined by the Vibrating sample Magnetometer (VSM) model - LAKESHORE 7404 SERIES and a scanning electron microscope (SEM). The sol-gel process was performed in a clean room for an accuracy purpose.

\section{Results and discussion}

\subsection{XRD analysis}

A magnetic nanoparticle of $\mathrm{Cafe}_{2} \mathrm{O}_{4}$ was successfully obtained according to the mentioned preparation process. The X-ray diffraction pattern for $\mathrm{CaFe}_{2} \mathrm{O}_{4}$ is shown in (Figure 3). XRD analysis was performed after a calcination at $550^{\circ} \mathrm{C}$. The sample calcined at $550^{\circ} \mathrm{C}$ is characterized by a broad peak, which is typical for nanocrystalline structures of $\mathrm{CaFe}_{2} \mathrm{O}_{4}$, at around $2 \theta=20-80$. All the peaks indexed to the orthorhombic structure diffraction peak are well matched with the standard $\mathrm{CaFe}_{2} \mathrm{O}_{4}$ spectra (JCPDS 78-4321), which has been allocated to the typical crystal plane of calcium ferrite with good purity of $\mathrm{CaFe}_{2} \mathrm{O}_{4}$ [34]. The average crystallite size was calculated using the Scherer equations (1):

$$
D=K \lambda / \beta \cos \theta
$$

where $\mathrm{K}$ is the Scherer constant $(\mathrm{K}=0.89), \lambda$ is the $\mathrm{X}$-ray wavelength, $\beta$ is the peak width at half maximum, and $\theta$ is the Braggs diffraction angle [35]. For $\mathrm{CaFe}_{2} \mathrm{O}_{4} \mathrm{NPs}$, an average crystal size of $13.59 \mathrm{~nm}$ was calculated. 


\subsection{Magnetic property analysis}

The hysteresis curve of the synthesized $\mathrm{CaFe}_{2} \mathrm{O}_{4}$ NPs was measured using a VSM at room temperature (Figure 4). The samples were taken from $\mathrm{CaFe}_{2} \mathrm{O}_{4}$ after the calcination process at $550^{\circ} \mathrm{C}$. It is apparent from the figure that the magnetization of calcium ferrite nanoparticles results in high superparamagnetic behavior at room temperature in S1, while magnetic saturation Ms value of 88.3 $\mathrm{emu} / \mathrm{g}$ is calculated per gram of the sample at room temperature. Magnetization constantly increased and became saturated for uncoated samples at higher fields. The coercivity (Hci) value was $85.331 \mathrm{G}$.

Moreover, sample S2 and S3 indicate to the sample synthesized with surfactant addition. The polyvinylpyrrolidone (PVP) and polyvinyl alcohol (PVP) as surfactant were tested which were initially aimed to control the crystal size. In comparison to sample S2 and S3, it is clearly seen that the Ms of both samples have much lower magnetization which attributed to the surface effect. The use of surfactant will be further experimented in order to find optimum mix composition for uniform particle size distribution.

In addition, the synthesized calcium ferrite nanoparticles reveal that superparamagnetic behavior is supreme for biomedical application [35].

\subsection{SEM and EDX analysis}

The surface microstructure of $\mathrm{CaFe}_{2} \mathrm{O}_{4} \mathrm{NPs}$ was studied by observing the SEM image. The SEM photograph of $\mathrm{CaFe}_{2} \mathrm{O}_{4}$ provides the shape of the particles. The nanoparticles calcined at $550^{\circ} \mathrm{C}$ provide the spherical nanoparticles. Results showed that the higher the calcination temperature, the bigger particles were absorbed. However, the agglomeration of $\mathrm{CaFe}_{2} \mathrm{O}_{4}$ was caused by the high surface energy and magnetic interaction among the crystals (see Figure 5(a)). In Figure 5(b), EDX analysis from the spectrum shows that the $\mathrm{Fe}, \mathrm{Ca}$, and $\mathrm{O}$ elements are present in the sample as the synthesized $\mathrm{CaFe}_{2} \mathrm{O}_{4}$ are formed.

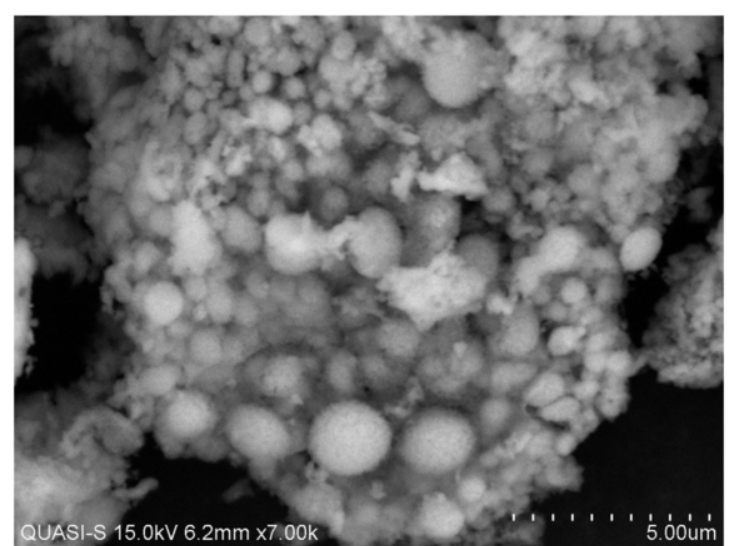

(a)

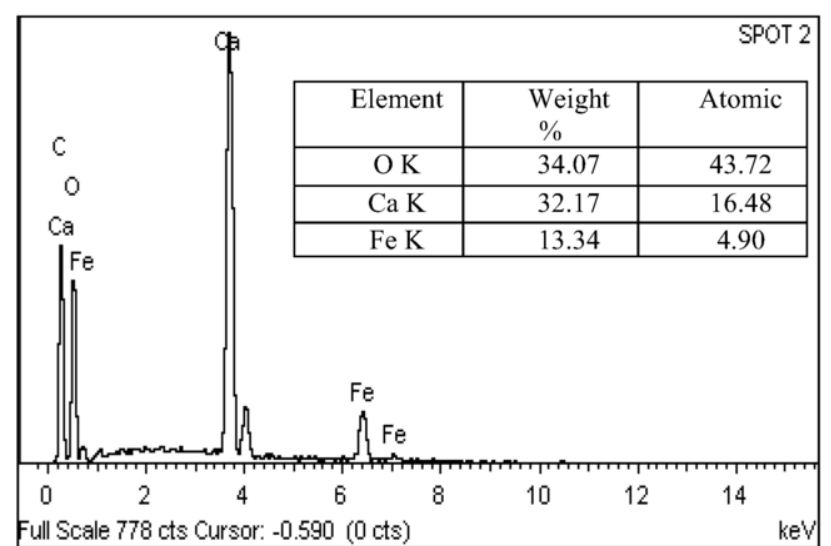

(b)

Fig. 5. (a) SEM image of synthesized calcium ferrite NPs, (b) nano-particles characteristic form EDX measurement. 


\section{Conclusions}

In this paper, magnetic calcium ferrite nano-particles were synthesized using sol-gel method. According to the results, this method demonstrated a number of advantages, such as being a simple process that was accurate and satisfactory and gives pure magnetic material. The structure of magnetic $\mathrm{CaFe}_{2} \mathrm{O}_{4}$ nanoparticles and their magnetic properties were studied using XRD and VSM analysis, respectively. The XRD results confirm an orthorhombic structure while the VSM results show that the

$\mathrm{CaFe}_{2} \mathrm{O}_{4} \mathrm{NPs}$ have superparamagnetic characteristics through the magnetization saturation of $88.3 \mathrm{emu} / \mathrm{g}$. The magnetic study of the synthesized materials shows that the $\mathrm{CaFe}_{2} \mathrm{O}_{4}$ based NPs would be promising materials for targeted drug delivery.

\section{Acknowledgment}

The author, gratefully thank to Dr. Muneer M. Ba-Abbad Department of Chemical and Process Engineering, Faculty of Engineering and Built Environment, Universiti Kabangsaan Malaysia for his supported.

\section{References}

[1] N. Ikenaga, Y. Ohgaito and T. Suzuki, H2S absorption behavior of calcium ferrite prepared in the presence of coal, Energy Fuels 19 (2005), 170-179.

[2] D. Hirabayashi, Y. Sakai, T. Yoshikawa, K. Mochizuki, Y. Kojima, K. Suzuki, K. Ohshita and Y. Watanabe, Mössbauer characterization of calcium ferrite oxides prepared by calcining $\mathrm{Fe}_{2} \mathrm{O}_{3}$ and $\mathrm{CaO}$, Hyperfine Interact 167 (2006), 809-813.

[3] Samariya S.N. Dolia, A.S. Prasad, P.K. Sharma, S.P. Pareek, M.S. Dhawan and S. Kumar, Size dependent structural and magnetic behavior of $\mathrm{CaFe}_{2} \mathrm{O}_{4}$, Current Applied Physics 13 (2013), 830-835.

[4] Corot P. Robert, J.M. Idée and M. Port, Recent advances in iron oxide nanocrystal technology for medical imaging, Advanced Drug Delivery Reviews 58 (2006), 1471-1504.

[5] Akbarzadeh N. Zarghami, H. Mikaeili, D. Asgari. A.M. Goganian, H.K. Khiabani, M. Samiei and S. Davara, Synthesis, characterization, and in vitro evaluation of novel polymer-coated magnetic nanoparticles for controlled delivery of doxorubicin, Nanotechnology and Science Application 5 (2012), 13-25.

[6] J.W.M. Bulte, T. Douglas, B. Witwer, S.C. Zhang, E. Strable, B.K. Lewis, H. Zywicke, B. Miller, P.V. Gelderen, B.M. Moskowitz, I.D. Duncan and J.A. Frank, Magnetodendrimers allow endosomal magnetic labeling and in vivo tracking of stemcells, Nature Biotechnology 19 (2001), 1141-1147.

[7] O. Olsvik, T. Popovic, E. Skjerve, K.S. Cudjoe, E. Hornes, J. Ugelstad and M. Uhlen, Magnetic separation techniques in diagnostic microbiology, Clinical Microbiology Reviews 7 (1994), 43-54.

[8] F. Scherer, M. Anton, U. Schillinger, J. Henke, C. Bergemann, A. Krüger, B. Gänsbacher and C. Plank, Magnetofection: Enhancing and targeting gene delivery by magnetic force in vitro and in vivo, Gene Therapy 9 (2002), 102-109.

[9] Y.X. Wang, S.M. Hussain and G.P. Krestin, Superparamagnetic iron oxide contrast agents: Physicochemical characteristics and applications in MR imaging, European Radiology 11 (2001), 2319-2331.

[10] M. Johannsen, U.G. Eckelt, A. Feussner, N. Waldofner, R. Scholz, S. Deger, P. Wust, S.A. loaning and A. Jordan, Clinical hyperthermia of prostate cancer using magnetic nanoparticles: Presentation of a new interstitial technique, International Journal of Hyperthermia 21 (2005), 637-647.

[11] Alexiou W. Arnold, R.J. Klein, F.G. Parak, P. Hulin, C. Bergemann, W. Erhardt, S. Wagenpfeil and A.S. Lu"bb, Locoregional cancer treatment with magnetic drug targeting, Cancer Research 60 (2000), 6641-6648.

[12] A.S. Lubbe, C. Bergemann, H. Riess, F. Schriever, P. Reichardt, K. Possinger, M. Matthias, B. Dörken, F. Herrinann, R. Gurtler, P. Hohenberger, N. Haas, R. Sohr, B. Sander, A.J. Lemke, D. Ohlendorf, W. Huhnt and D. Huhn, Clinical experiences with magnetic drug targeting: A phase I study with 40- epidoxorubicin in 14 patients with advanced solid tumors, Cancer Research 56 (1996), 4686-4693. 
[13]L. Durães, B.F.O Costa, J. Vasques, J. Campos and A. Portugal, Phase investigation of as-prepared iron oxide/hydroxide produced by sol-gel synthesis, Materials Letters 59 (2005), 859-863.

[14] R.A. Candeiaa, M.I.B. Bernardib, E. Longoc, I.M.G. Santosa and A.G. Souza, Synthesis and characterization of spinel pigment $\mathrm{CaFe}_{2} \mathrm{O}_{4}$ obtained by the polymeric precursor method, Materials Letters 58 (2004), 569-572.

[15] M. Dadwal, Polymeric nanoparticles as promising novel carriers for drug delivery: An overview, Journal of Advanced Pharmacy Education \& Research 4 (2014), 20-30.

[16] L.J. Berchmans, M. Myndyk, K.L. Da Silva, A. Feldhoff, J. Subrt, P. Heitjans, K.D. Becker and V. Sepelák, A rapid one-step mechanosynthesis and characterization of nanocrystalline $\mathrm{CaFe}_{2} \mathrm{O}_{4}$ with orthorhombic structure, Journal of Alloys and Compounds $\mathbf{5 0 0}$ (2010), 68-73.

[17] R. Dom, R. Subasri, K. Radha, Pramod and H. Borse, Synthesis of solar active nanocrystalline ferrite, $\mathrm{MFe}_{2} \mathrm{O}_{4}(\mathrm{M}: \mathrm{Ca}$, $\mathrm{Zn}, \mathrm{Mg}$ ) photocatalyst by microwave irradiation, Solid State Communications 151 (2011), 470-473.

[18] J.G. Baldha, R.V. Upadhyay and R.G. Kulkarni, On the substitution of calcium in cobalt ferrite, Journal of Material Science 23 (1988), 3357-3361.

[19]Z. Dai, F. Meiser and H. Möhwald, Nanoengineering of iron oxide and iron oxide/silica hollow spheres by sequential layering combined with a sol-gel process, Journal of Colloid and Interface Science 288 (2005), 298-300.

[20]K. Kojima, M. Miyazaki, F. Mizukami and K. Maeda, Selective formation of spinel iron oxide in thin films by complexing agent-assisted sol-gel processing, Journal of Sol-Gel Science and Technology 8 (1997), 77-81.

[21] M.J. Pirouz, M.H. Beyki and F. Shemirani, Anhydride functionalized calcium ferrite nanoparticles: A new selective magnetic material for enrichment of lead ions from water and food samples, Food Chemistry 170 (2015), 131-137.

[22] S.C. McBain, H. HP. Yin and J. Dobson, Magnetic nanoparticles for gene and drug delivery, International Journal of Nanomedicine 3 (2008), 169-180.

[23] Q.A. Pankhurst, J. Connolly, S.K. Jones and J. Dobson, Applications of magnetic nanoparticles in biomedicine, Journal of Physics D: Applied Physics 36 (2003), 167-181.

[24] M.H. Amtenbrink and B.V. Rechenberg, Superparamagnetic nanoparticles for biomedical applications, Nanostructured Materials for Biomedical Applications 37 (2009), 119-149.

[25] A.H. Lu, E.L. Salabas and F. Schüth, Magnetic nanoparticles: Synthesis, protection, functionalization and application, Chemie International Edition 46 (2007), 1222-1244.

[26] K.K. Jain, Drug delivery systems, Methods in Molecular Biology 437 (2008), 1-50.

[27] M. Arruebo, R.F. Pacheco, M. Ricardo Ibarra and J. Santamaría, Magnetic nanoparticles for drug delivery, Nano Today 2 (2007), 22-32.

[28] F. Dumestre, B. Chaudret, C. Amiens, P. Renaud and P. Fejes, Superlattices of iron nano-cubes synthesized from $\mathrm{Fe}\left[\mathrm{N}\left(\mathrm{SiMe}_{3}\right)_{2}\right]_{2}$, Science 303 (2004), 821-823.

[29] S.J. Park, S. Kim, S. Lee, Z. G. Khim, K. Char and T. Hyeon, Synthesis and magnetic studies of uniform iron nanorods and nanospheres, Journal of American Chemical Society 122 (2000), 8581-8582.

[30] J. lee, T. Isobe and M. Senna, Preparation of ultrafine $\mathrm{Fe}_{3} \mathrm{O}_{4}$ particles by precipitation in the presence of PVA at high $\mathrm{pH}$, Journal of Colloid and Interface Science 177 (1996), 490-494.

[31] A.K. Gupta and M. Gupta, Synthesis and surface engineering of iron oxide nanoparticles for biomedical applications, Biomaterials 26 (2005) 3995-4021.

[32] T. Neuberger, B. Schöpf, H. Hofmann, M. Hofmann and B. Rechenberg, Superparamagnetic nanoparticles for biomedical applications, possibilities and limitations of a new drug delivery system, Journal of Magnetism and Magnetic Materials 293 (2005), 483-496.

[33] S.R. Mudshinge, A.B. Deore, S. Patil and C.M. Bhalgat, Nanoparticles: Emerging carriers for drug delivery, Saudi Pharmaceutical Journal 19 (2011), 129-141.

[34]H.P. Klug and L.E. Alexander, X-ray Diffraction Procedures for Polycrystalline and Amorphous Materials, Wiley, New York, 1974.

[35] L. Khanna and N.K. Verma, Synthesis, characterization and in vitro cytotoxicity study of calcium ferrite nanoparticles, Materials Science in Semiconductor Processing 16 (2013), 1842-1848. 